\title{
Why hamstring eccentrics are hamstring essentials
}

\author{
Kristian Thorborg ${ }^{1,2}$
}

$\boldsymbol{\sigma}$ EDITOR'S CHOICE
There is no dispute that acute hamstring injury is a major sports injury, ${ }^{1-6}$ particularly in football codes $^{2} 356$ and other sports that demand high-speed running. ${ }^{1}$ The purpose of this editorial is to provide the reader with evidence-based tips for optimising hamstring injury prevention.

\section{THE RETURN-TO-SPORT HUSTLE} Gambling early return against recurrence Early return to sport ( $\leq 3$ weeks) is often proposed for hamstring injuries, ${ }^{7}$ even though basic research clearly shows that ongoing muscle regeneration still occurs, ${ }^{8}$ and the risk of recurrence is dramatically increased at this point. ${ }^{7}$ Recurrence includes possible additional injury and non-optimal healing of the hamstring muscle-tendinous complex. ${ }^{9}$ Such an injury can cause an athlete severe hamstring problems up to a year. ${ }^{610}$

Therefore, to manage hamstring injuries properly, it is important to address one of the main problems - the extremely high recurrence rate $e^{567}$ - which includes everything from exacerbation to reinjury. ${ }^{11}$ The acute hamstring injury and its recovery can be difficult for most lay people (including athletes and coaches) to comprehend, as jogging and moderatepaced running is often possible early after the injury - suggesting that full recovery is close. However, because the eccentric capacity (the ability to dissipate forces through lengthening contractions) of the hamstring muscle-tendinous complex is not challenged until the introduction of high-paced running, ${ }^{12} 13$ full recovery can still be weeks/months away.

My own experience is that athletes, coaches and medical personnel are often overoptimistic in their evaluation of when the athlete should return after a hamstring injury. The classic example is the principle often applied in soccer, where a player is

\footnotetext{
${ }^{1}$ Arthroscopic Centre Amager, Copenhagen University Hospital, Hvidovre, Copenhagen, Denmark

2Department of Orthopaedic Surgery and Physical Therapy, Copenhagen University Hospital, Hvidovre, Copenhagen, Denmark

Correspondence to Kristian Thorborg, Arthroscopic Centre Amager, Copenhagen University Hospital, Hvidovre, Copenhagen, Denmark;

kristianthorborg@hotmail.com
}

deemed ready to play if he can fully participate in the last training session the day or two before a game. This is not a good criterion for return to sport for a soccer player with a recent hamstring injury as match play has 15 times the risk of injury as does a training session. ${ }^{6}$ Important factors, such as high-speed running, muscle fatigue and competitiveness are not tested as much in a training session that often consists of smallsided games and more specific soccer drills.

Askling etal's ${ }^{14}$ importantworkalso highlights the problem of a very early return to sport. Isometric hamstring muscle strength in sprinters was $70 \%$ (2 weeks), $85 \%$ (3 weeks) and $90 \%$ (6 weeks) that of the uninjured limb after an initial hamstring muscle

\section{"Early return to \\ Nordic hamstring prevents injuries and re-injuries} sport has poor odds for success and is likely to fail in a large proportion of cases."

injury. The actual time before these injured athletes felt they were back at their preinjury level was a median of 16 weeks (range 6-50 weeks). Verrall et al ${ }^{15}$ also showed that coach ratings of player performance were significantly lower immediately upon return to sport when compared with ratings for the entire season, and when compared with ratings from the two games before injury.

Given that athletes ${ }^{14}$ and coaches $^{15}$ report that performance during early return to sport is reduced, it must be prudent to delay return to sport. Not only are athletes at greater risk of recurrence, which would potentially sideline them for an even longer period than the initial injury, ${ }^{29}$ they are also physically and mentally functioning at a lower level; ${ }^{14} 15$ in short, early return to sport has poor odds for success and is likely to fail in a large proportion of cases.

\section{Criteria for return-to-sport should be hamstring function dependent, not time dependent}

More so, clinical decisions regarding return to sport after hamstring injuries should be based on specific criteria, instead of being time determined. Specific criteria should include reliable and valid assessments involving hamstring muscle lengthening and contraction performed under controlled test conditions. Providing specific data on hamstring strength recovery, ${ }^{10} 14$ self-reported insecurity/pain during ballistic hamstring flexibility movements (Askling's H-test), ${ }^{16}$ and relevant sportsspecific activities, such as high-intensity running performance, ${ }^{17}$ can be a real eye opener to athletes and coaches regarding hamstring recovery and function. In elite environments where competitive and economical agendas may influence clinical decision making, continuous assessment and data collection are valuable instruments when attempting to promote optimal return to sport. That said, avoiding early exacerbation and re-injury at the elite level is a complex task that is neither easy, nor currently documented. However, new evidence indicates that later re-injuries can now be dramatically reduced, also at the elite level. ${ }^{18}$

In a recent large-scaled randomised controlled trial, by Petersen et al, ${ }^{18}$ including 942 soccer players, we addressed the efficacy of the Nordic hamstring exercise program for preventing acute hamstring injuries in soccer, ${ }^{18}$ and were particularly interested in its effect on re-injuries. The study showed that by intervening with one simple exercise, the Nordic hamstring exercise, in a progressive 10 -week program, as introduced by Mjølsnes et al, ${ }^{19}$ acute hamstring injuries (new injuries and re-injuries) could be reduced by $70 \%{ }^{18}$ These findings concur with the quasiexperimental study by Arnason et a ${ }^{20}$ who reported a $65 \%$ lower injury incidence in soccer players completing a 10 -week intervention consisting of warm-up stretching, flexibility training and the Nordic hamstring exercise program, compared with a group performing warm-up stretching and flexibility training alone. The results of the study by Petersen et a l $^{18}$ indicate that the preventive effect is solely a result of the Nordic hamstring exercise program.

Even more interesting was the fact that re-injuries alone were reduced by $85 \%$ in the group that performed the Nordic hamstring exercise program. ${ }^{18}$ The study showed that in order to prevent one reinjury, only three players at high risk (players with a hamstring injury in the previous year) had to perform the program. ${ }^{18}$ Thus, the number needed to treat (NNT), is much lower than the threshold 
considered acceptable in cardiovascular diseases or cancer where 10-100 or more is often celebrated. ${ }^{21}$ The NNT for preventing one anterior cruciate ligament injury using neuromuscular training programs, is around 90 athletes. ${ }^{22}$ It is thus incontrovertible that the Nordic hamstring exercise program reduces hamstring injuries. It could almost be considered negligent not to provide eccentric hamstring strengthening in this form for athletes with a history of previous hamstring injury (ie, athletes at high risk of re-injury).

These spectacularly good results do not come from left field. Croisier et a ${ }^{10}$ reported a $100 \%$ success rate (no re-injury the following year) after introducing progressive isokinetic strength training (including both concentric and eccentric contractions), performed three times a week, continued until bilateral strength and eccentric strength deficits in the hamstrings were normalised. Strength normalisation occurred from 4 to 10 weeks for the included athletes. ${ }^{10}$ Taken together with Petersen et al's data, ${ }^{18}$ systematic and progressive eccentric strengthening has a large hamstring re-conditioning capability, most likely addressing eccentric strength deficits, ${ }^{10}$ muscle-tendinous atrophy and scar tissue, ${ }^{23}$ certainly changing the injury risk profile of the athlete with a previous hamstring strain, even when addressed somewhat later than the initial injury and rehabilitation. ${ }^{18}$ The physiological adaptation to hamstring lengthening contractions, ${ }^{10}$ 17-19 therefore, also seem consistent with the physiological process of mechanotransduction and mechanotherapy. 2425

\section{Hamstring exercise theories and anecdotes}

What the precise preventive injury mechanism related to the eccentric strength training is, remains uncertain, ${ }^{26}$ and the debate is ongoing. ${ }^{26} 27$ Basic researchers have provided different theories on the subject, where the most prominent one is that a shift in the optimum angle for torque generation, to longer hamstring muscle lengths, as a response to eccentric strength training, can protect against hamstring injuries and re-injuries. ${ }^{27} 28$ Furthermore, studies of the biomechanics of running have provided evidence that peak muscle-tendinous force and strain for the hamstring muscle complex occur during the terminal swing phase, just before ground contact, and it is suggested that it is in this period of the stride cycle that the biarticular hamstrings are at the greatest risk of injury. ${ }^{26} 29$ This injury-mechanism

\section{Hlstory of hamstring eccentrics for injury prevention and their application}

Nordic hamstrings have previously also been referred to as Russian hamstrings. ${ }^{35}$ The term 'Nordic hamstring' was introduced in the scientific sports medicine literature in 2004 by Mjølsnes et a/ ${ }^{19}$ who introduced the 10 -week Nordic hamstring exercise program, included for hamstring injury prevention in a quasi-experimental trial by Arnason et al in $2008,{ }^{20}$ and in a randomised clinical trial by Petersen et al in $2011 .{ }^{18}$ Brockett et al had already described and proposed the exercise (naming it hamstring lowers) for hamstring injury prevention in 2001, ${ }^{28}$ and a specific program was later described and implemented in a randomised hamstring injury prevention trial by Gabbe et al. ${ }^{33}$ There are, however, some important differences between the two training programs - Nordic hamstrings ${ }^{18} 19$ and the hamstring lowers ${ }^{28} 33$ - concerning exercise period, progression model, number of sessions, sets and total workload. The Nordic hamstring 10-week exercise program includes a total of 27 sessions, and starts out with only 10 repetitions in a single session the first week, and then slowly progresses, ending with 30 repetitions three times a week, from week 5 to $10 .^{1819}$ The hamstring lowers program has been applied including five sessions during 12 weeks, including a total of 72 repetitions ( $6 \times 12$ reps) in each session, with 2-3 weeks between sessions. ${ }^{33}$ While the Nordic hamstring program induced minimal DOMS, with a mean of 1 on a visual analogue scale, after the first session, ${ }^{19}$ the hamstring lowers program has been reporting a mean DOMS of 5.5 after the first session, ${ }^{28}$ supporting the apparent impression that this includes a much more aggressive first-session approach, compared to the Nordic hamstring program.

theory has now been confirmed in two independent case reports with actual video footage of hamstring injuries occurring during high-speed running. ${ }^{30} 31$

It has therefore been suggested that eccentric muscle strength training should be performed at longer muscle-tendinous lengths, preferentially mimicking movements and muscle length occurring at both the knee and the hip, simultaneously. $^{26} 29$ On that note, I have often overheard the Nordic Hamstring exercise being criticised by physical trainers and exercise therapists, as they felt that this exercise was not specific enough in mimicking basic running mechanics, and thereby not effective for preventing hamstring injuries. ${ }^{32}$ In fact, there are opinions in the strength/conditioning and rehabilitation environment, that the Nordic Hamstring exercise is contraindicated for hamstring injury prevention, ${ }^{32}$ because of anecdotal evidence that the excessive stress to the hamstring muscle complex predisposes athletes to hamstring injury ${ }^{32}$ or significant delayed onset muscle soreness (DOMS). ${ }^{33}$ Information concerning possible harmful effects should never be ignored in clinical practice; however, these unfortunate experiences may be explained by overly aggressive introduction of the exercise. $^{2833}$

\section{Optimum titration of the nordic hamstring program}

We carefully applied the Nordic hamstring exercise program from January/February in the midseason break, introducing one session (week 1), then progressing to two sessions (week 2) and three sessions (from week 3-10), and finally continuing with one session per week (after week 10) for hamstring strength maintenance through the rest of the following year. ${ }^{18}$ This allowed for timing the physiological adaptive response, including minimal initial DOMS ${ }^{18}$ and increased eccentric strength to occur ${ }^{19}$ before the big spike in hamstring injuries that we have observed in Danish soccer in the spring, ${ }^{6}$ as the games in the second half of the season commences. No differences in injury rate or any adverse effects related to the training were reported during the 10 -week intervention period of this trial. ${ }^{18}$

Therefore, implementing the Nordic hamstring exercise program (level 1 evidence), ${ }^{34}$ when dealing with highspeed running athletes, seems straight forward. It requires an understanding of the following: specific hamstring eccentrics (Nordic hamstrings) - why they are essential - and how they can be implemented in a safe and systematic way.

Funding This work was funded by the Arthroscopic Centre Amager, Copenhagen University Hospital, Hvidovre, Copenhagen, Denmark and Departments of Orthopaedic Surgery and Physical Therapy, Copenhagen University Hospital, Hvidovre, Copenhagen, Denmark.

\section{Competing interests None.}

Provenance and peer review Not commissioned; externally peer reviewed.

Received 13 January 2012

Accepted 11 March 2012

Br J Sports Med 2012;46:463-465. doi:10.1136/bjsports-2011-090962 


\section{REFERENCES}

1. Bennell KL, Crossley K. Musculoskeletal injuries in track and field: incidence, distribution and risk factors. Aust J Sci Med Sport 1996;28:69-75.

2. Brooks JH, Fuller CW, Kemp SP, et al. Incidence, risk, and prevention of hamstring muscle injuries in professional rugby union. Am J Sports Med 2006;34:1297-306

3. Hägglund $\mathbf{M}$, Waldén $\mathbf{M}$, Ekstrand J. Injuries among male and female elite football players. Scand J Med Sci Sports 2009;19:819-27.

4. Heiderscheit BC, Sherry MA, Silder A, et al. Hamstring strain injuries: recommendations for diagnosis, rehabilitation, and injury prevention. J Orthop Sports Phys Ther 2010;40:67-81.

5. Orchard J, Seward H. Epidemiology of injuries in the Australian Football League, seasons 1997-2000. Br J Sports Med 2002;36:39-44.

6. Petersen J, Thorborg K, Nielsen MB, et al. Acute hamstring injuries in Danish elite football: a 12-month prospective registration study among 374 players. Scand J Med Sci Sports 2010;20:588-92.

7. Orchard J, Best TM. The management of muscle strain injuries: an early return versus the risk of recurrence. Clin J Sport Med 2002;12:3-5

8. Best TM, Shehadeh SE, Leverson G, et al. Analysis of changes in mRNA levels of myoblast- and fibroblastderived gene products in healing skeletal muscle using quantitative reverse transcription-polymerase chain reaction. J Orthop Res 2001;19:565-72.

9. Koulouris G, Connell DA, Brukner P, et al. Magnetic resonance imaging parameters for assessing risk of recurrent hamstring injuries in elite athletes. $\mathrm{Am} \mathrm{J}$ Sports Med 2007;35:1500-6.

10. Croisier JL, Forthomme B, Namurois $\mathrm{MH}$ et al. Hamstring muscle strain recurrence and strength performance disorders. Am J Sports Med 2002;30:199-203.

11. Fuller CW, Bahr R, Dick RW, et al. A framework for recording recurrences, reinjuries, and exacerbations in injury surveillance. Clin J Sport Med 2007;17:197200.

12. Chumanov ES, Heiderscheit BC, Thelen DG. The effect of speed and influence of individual muscles on hamstring mechanics during the swing phase of sprinting. J Biomech 2007;40:3555-62.
13. Schache AG, Blanch PD, Dorn TW, et al. Effect of running speed on lower limb joint kinetics. Med Sci Sports Exerc 2011;43:1260-71

14. Askling C, Saartok T, Thorstensson A. Type of acute hamstring strain affects flexibility, strength, and time to return to pre-injury level. Br J Sports Med 2006;40:40-4.

15. Verrall GM, Kalairajah Y, Slavotinek JP, et al. Assessment of player performance following return to sport after hamstring muscle strain injury. J Sci Med Sport 2006; 9:87-90.

16. Askling CM, Nilsson J, Thorstensson A. A new hamstring test to complement the common clinical examination before return to sport after injury. Knee Surg Sports Traumatol Arthrosc 2010:18:1798-803.

17. Askling C, Karlsson J, Thorstensson A. Hamstring injury occurrence in elite soccer players after preseason strength training with eccentric overload. Scand J Med Sci Sports 2003;13:244-50.

18. Petersen J, Thorborg K, Nielsen MB, et al. Preventive effect of eccentric training on acute hamstring injuries in men's soccer: a clusterrandomized controlled trial. Am J Sports Med 2011;39:2296-303

19. Mjølsnes R, Arnason A, Østhagen T, et al. A 10 -week randomized trial comparing eccentric vs. concentric hamstring strength training in welltrained soccer players. Scand J Med Sci Sports 2004:14:311-17.

20. Arnason A, Andersen TE, Holme I, et al. Prevention of hamstring strains in elite soccer: an intervention study. Scand J Med Sci Sports 2008;18:40-8.

21. Artalejo FR, Banegas JR, Artalejo AR, et al. Number-needed-to-treat to prevent one death. Lancet 1998;351:1365.

22. Grindstaff TL, Hammill RR, Tuzson AE, et al. Neuromuscular control training programs and noncontact anterior cruciate ligament injury rates in female athletes: a numbers-needed-to-treat analysis. $J$ Athl Train 2006;41:450-6.

23. Silder A, Heiderscheit BC, Thelen DG, et al. MR observations of long-term musculotendon remodeling following a hamstring strain injury. Skeletal Radiol 2008;37:1101-9.
24. Khan KM, Scott A. Mechanotherapy: how physical therapists' prescription of exercise promotes tissue repair. Br J Sports Med 2009;43:247-52.

25. Kjær M. Role of extracellular matrix in adaptation of tendon and skeletal muscle to mechanical loading. Physiol Rev 2004;84:649-98.

26. Thelen DG, Chumanov ES, Sherry MA, et al. Neuromusculoskeletal models provide insights into the mechanisms and rehabilitation of hamstring strains. Exerc Sport Sci Rev 2006;34:135-41.

27. Proske U, Morgan DL, Brockett CL, et al. Identifying athletes at risk of hamstring strains and how to protect them. Clin Exp Pharmacol Physiol 2004;31:546-50.

28. Brockett CL, Morgan DL, Proske U. Human hamstring muscles adapt to eccentric exercise by changing optimum length. Med Sci Sports Exerc 2001;33:783-90

29. Schache AG, Dorn TW, Blanch PD, et al. Mechanics of the Human Hamstring Muscles during Sprinting. Med Sci Sports Exerc 2011 (In Press).

30. Heiderscheit BC, Hoerth DM, Chumanov ES, et al. Identifying the time of occurrence of a hamstring strain injury during treadmill running: a case study. Clin Biomech (Bristol, Avon) 2005;20:1072-8.

31. Schache AG, Kim HJ, Morgan DL, et al. Hamstring muscle forces prior to and immediately following an acute sprinting-related muscle strain injury. Gait Posture 2010;32:136-40.

32. Gambetta V, Benton D. A systematic approach to hamstring prevention and rehabilitation. Sports Coach 2008;28:1-6.

33. Gabbe BJ, Branson R, Bennell KL. A pilot randomised controlled trial of eccentric exercise to prevent hamstring injuries in community-level Australian Football. J Sci Med Sport 2006;9:103-9.

34. Oxford Centre for Evidence-based Medicine Levels of Evidence (March 2009). http://www.cebm.net/index. aspx? $0=1025$ (accessed January 2012).

35. Gilchrist J, Mandelbaum BR, Melancon $\mathrm{H}$, et al. A randomized controlled trial to prevent noncontact anterior cruciate ligament injury in female collegiate soccer players. Am J Sports Med 2008:36:1476-83. 